\title{
Wife battery: Preliminary survey of fifty one cases and literature review
}

\author{
Nandasiri C, Ruwanpura R, Senerath $\mathbf{P}$ \\ Teaching Hospital Karapitiya, Galle, Sri Lanka \\ Correspondence: Dr. Rohan Ruwanpura \\ e-mail:rohanr@mobitelnet.lk
}

\begin{abstract}
Introduction: This paper presents wife battery in Southern region of Sri Lanka, as a part of a worldwide phenomenon. Due to hidden nature of the problem accurate statistics are hard to come out by victims.

Methods: This was a two-year prospective study to determine the prevalence of domestic violence against women and its associated features in cases presented to Teaching Hospital Karapitiya, Galle, commencing November 2008. The present paper deals with preliminary survey of 51 cases investigated at our unit up to July 2009.

Results: There had been 2400 cases admitted to casualty wards of the Karapitiya Hospital with medico-legal references from the police stations in Southern Province, during this period and 51 women out of the total number who complained of physical assault by their husbands were interviewed. The majority victims had presented with bruising, often together with other injuries such as lacerations and fractures. The higher prevalence of violence was observed in families with problems of chronic alcoholism and other anti-social habits. The educational standards of both wives and husbands spanned over a wide range from primary schooling to university level. The study revealed a significant association between the level of husband's education and incidence of violence against the women. The impact of the husband's job and economic status of the family on frequency of domestic quarrel was also observed. We observed that the victims of wife battery did not always leave the abusive environment probably because of lack of family and community support.
\end{abstract}

Conclusion: Wife battery has clear associations and these can be used in recognizing high risk family situations. Wife battery must be discouraged through litigation, general education and economic empowerment of women.

\section{Introduction}

It has been noted worldwide, that one of the most common forms of violence against women (VAW) is abuse by their husbands or other intimate male partners. Wife beating has been condoned throughout the history of mankind. The first known written laws (about 2500 B.C.) proclaimed that the name of any woman who verbally abused her husband was to be engraved on a brick which was then to be used to dash out her teeth. A physical punishment of a wife was a recognized right of men in Greek and Roman societies and was accepted by Jewish, Christian and Islamic authorities as well (1).
Partner abuse exists in a variety of forms including physical assault such as punching, slapping, kicking, and beatings; psychological abuse, such as constant belittling, intimidation, and humiliation; and coercive sex. Physical abuse is the most visible of all kinds of wife battery whereas psychological abuse is usually non-exhibiting in majority cases.

Domestic violence has gained considerable public attention during past few decades. In Western countries places of refuge for battered wives have been established, and police, social workers, doctors and women's groups have been alerted to the problem. 
The present study was conducted to ascertain the nature and circumstances of violence against women. In this survey a battered wife was defined as a woman who had received deliberate severe and repeated demonstrable physical injury from her husband.

\section{Methods}

The data and Information were obtained during medico-legal examinations, using an open questionnaire and the personal interview of consenting women claiming physical assault by their husbands. Most victims were inward patients of Teaching Hospital, Karapitiya and others were directly referred by the police for medico legal purposes, both categories with medico-legal examination forms. Details were summarized, analyzed and compared with currently available literature sources.

\section{Results}

\section{Physical injuries}

Of 51 cases, 18 cases presented with abrasions and 27 cases had contusions. Lacerations were present in 4 cases, and in 3 cases, victims were bitten by their husbands. Only four victims had more than one type of injury (Figure).

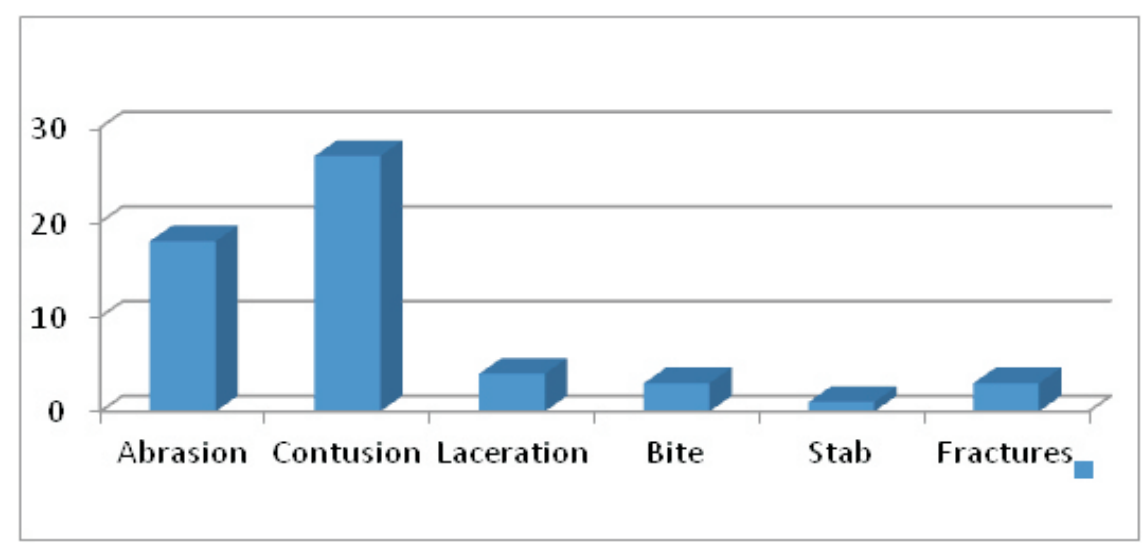

Figure: Prevalence of injury types

Almost all injuries were of non-grievous category except three cases, those presented with grievous injuries namely, fractures. Injuries, either nongrievous or grievous were exclusively caused by application of blunt forces. Weapons were used in 23 cases and commonly available domestic objects such as clubs and wooden poles had been used in 14 cases. Two were stoned, and a wire, a shaver, a chair and a slipper had been used in solitary incidents. Only in one case, the victim was stabbed by her husband using table knife inflicting a superficial cut injury. There was an exclusive case, where the woman was pushed out from a moving vehicle. In all cases physical assaults were preceded/ accompanied by psychological abuse. All incidents of physical abuse had taken place within their residential premises.

\section{Other background factors}

A large majority of the victims (41women) were married for over 5 years, while 9 victims revealed marital life from 2 to 5 years. In one case, duration of marital life was only 2 months.

In 35 families there were two or more children and 14 families had only one child. Two families had no children. The educational background of the victims revealed that 18 victims had received school education above the Grade 9, 20 victims had studied up to Year 9 or bellow and 12 had never been to a school (Table). No reliable data regarding husbands' education level were available.

In 41 cases, assailants were habitual alcoholics and 20 were smokers. Gambling was an issue in 2 cases. There were 4 assailants with sober habits, and nonsmokers. Most of the husbands were casual laborers and five were unemployed. Government servants and qualified professional partners were reported in 2 occasions. Most of the women were unemployed and entirely depended on her husband's earnings. 
Table: Circumstances and background factors $(\mathrm{n}=51)$

\begin{tabular}{lll}
\hline Characteristics studied & Range & Mean \\
\hline Age of the battered wife (yrs) & $23-59$ & 32.1 \\
Length of relationship (yrs) & $2-35$ & 9.6 \\
Age of leaving school (yrs) & $6-18$ & 11.5 \\
Age of husband (yrs) & $20-63$ & 35.5 \\
Number of children & $0-7$ & 2 \\
\hline
\end{tabular}

\section{Discussion}

Females may suffer from violence throughout their "life cycle" as fetuses may be aborted just because they are female, infants may be killed because they are female, girls may be neglected or subjected to various other types of abuse, adolescents may be raped, married women may be beaten, raped or killed by their husbands and widows may be neglected. The female infanticide and sex selective abortions that are caused by son-preference ideology have led to an imbalance in sex ratios characterized by millions of females "missing" from populations in Asia, China and North Africa. India is the site of approximately 5000 dowry related deaths each year (1). A survey of 1842 rural women of reproductive age in India revealed that both men and women consider wife beating acceptable and that $40 \%$ of all wives have been beaten by their husbands (1). In Bangladesh, a study carried out in a remote rural area during December 2000 indicates that $50.5 \%$ of the women were reported to be battered by their husbands and $2.1 \%$ by other family members (1). In the United Kingdom, two small studies reported lifetime prevalence of domestic violence against women of 39 and $60 \%(1,2)$. In North America (1), where women have equal rights and status, violence against women is still present in the society. Women numbering $40-51 \%$ experience some type of violence in their lifetime including child abuse, physical violence, rape and domestic violence. It is rather encouraging that, attempts to draw attention to the problem of violence against women as a serious social problem have ceased to be lonely voices in the wilderness. This is attested to by series of international conventions and local legislations which now make wife battery a criminal offence.
For example, the United Nations General Assembly passed the declaration of the Elimination of Violence against Women in 1993 (Population Reports XXVII 1999:5) (1). This was done through Resolution 48/104 (444). Also in 1995, the Fourth World Conference on Women, which took place in Beijing, China, advocated ending gender violence as a priority. In 1994 the Commission on Human Rights appointed the first special Rapporteur on violence against women and empowered her to investigate cases of abuse of human rights (Population Reports, op cit). These campaigns were designed to draw attention to the issue of violence against women. Finally, in 1999, the United Nations Population Fund declared violence against women a public health problem (1).

More than 160 countries have ratified the UN's Convention on the Elimination of All Forms of Violence against Women, and many countries have included provisions to protect women against violence in their constitutions and criminal codes. However, only 44 countries specifically protect women against Domestic violence (3).

The prevalence of women in this study who reported a history of physical violence from their partners is $12 \%$, when compared to total number of females admitted with injuries during the study period. More than $60 \%$ of women across Sri Lanka are victims of domestic violence while 44 per cent of pregnant women are also subjected to harassment, according to a 2006 survey by the Ministry of Child Development and Women's Empowerment (1). This is a significantly high ratio compared to what we found in our study. That may be due to the facts that our study represents only a part of Sri Lanka and 
figures might have been exaggerated, and there may be number of hidden cases which does not come to the attention of authorities.

The National Report on Violence and Health in Sri Lanka states that the cultural values inculcated in the minds of Sri Lankan women by the institution of marriage seems to have resulted in women continuing to remain in their marriage despite being in an abusive relationship.

The case studies conducted by Gayford revealed that, men with low frustration tolerance, who often completely lose control under the influence of alcohol, punch and kick their wives in a savage manner, perhaps using weapons to aid their assault (1). The general practitioner, usually one of the first outside the family to be trusted with her guilty secret, was more often presented with vague physical or mental symptoms. Even severe injuries were passed off as accidents. In many cases she was afraid to appear in public until the physical signs had subsided, but in a few cases she was made to parade her injuries as a sign of her husband's dominance. Suicidal gestures were usually treated in hospital without the true facts being revealed. Occasionally husbands prevented their wives from attending hospital for obviously needed medical attention, while others removed them prematurely. According to our data, longer the duration of marriage, the chances of battering is higher but the number of children does not play a significant role in wife battering. Study shows direct impact of alcohol abuse with incidence of spouse abuse. However, it is necessary to perform a broader society based surveys to reveal impact of alcohol abuse on prevalence of domestic violence. According to our general observations, there are many husbands of higher socio-educational background, who are regular alcohol consumers, but hardly abuse their spouses. The other significant factor associated with wife battering is poor socio-economic situation prevailing in majority affected families, though violence is present in few families with higher socio-economic status. These factors are common to other surveys from our region.

Women victimized by domestic violence suffer from more health problems than non-victimized women (1). Battered women are more likely to have been injured in the head, face, neck, thorax, breasts and abdomen than women injured in other ways (1).
The injury patterns of our victims were corroborative with the patterns described in above surveys. However, the severe maneuver like throwing out from the moving vehicle is an exclusive finding. The injuries fear, and stress associated with violence can result in chronic health problems such as chronic pain (e.g. headache, back pain), recurrent central nervous system symptoms including fainting and seizures, gastrointestinal disorders like loss of appetite, eating disorders or chronic irritable bowel syndrome, and also cardiac problems such as hypertension and chest pain (1).

Depression and post-traumatic stress disorder are the most prevalent mental health problems of domestic violence (1), though none of our victims showed severe psychological problems. These are mainly associated with emotionally abusive behaviors such as prohibiting a woman from seeing her family and friends, ongoing belittlement, humiliation, or intimidation, economic restrictions such as preventing a woman from working, or confiscating her earning and other controlling behavior, fear and stress due to physical abuse and forced sex. In a Canadian population based study, Ratner found that in addition to depression, abused women have also been associated with anxiety, insomnia and social dysfunction (1). But in our survey it was not elicited. Is violence passed on in familiesfiAs in cases of child abuse, it can be shown that the more violence an individual is exposed to during childhood, the more likely he is to be violent as an adult (1).

\section{Recommendations}

Patient guidance and support is essential to see even the more able and intelligent woman through this difficult period. A few women present as extremely damaged personalities who will need long-term support with their children (1).

General education and economic empowerment of the women is important. When women are educated, they stand better chances of being aware of and asserting their rights. It is also true that an educated woman who can assert her rights will find it easier to leave an abusive situation, because she can exist independently without being her husband's appendage. 
Such as illiterate unemployment, lower education for both men and women, placed our population at greater risk, so the topic of the outcome of domestic violence must be incorporated into the school and medical education curriculum.

Public education is a vital step, especially family life education in preparing young people for marital responsibilities and relationships. Education of the police and health workers is equally important, as many battered women report being told to return home, not be provocative or make matters worse. Certainly alcohol is the factor which most often precipitates violence. Counseling both parties before going to legal procedure may be helpful.

A major limitation of the study was the potential for bias in the given information. Women that experience domestic violence may be reluctant to acknowledge this because of shame or embarrassment.

\section{References:}

1. Violence against women: an issue of human rights. Gend Action 1997; 1(4): 1, 4, 8 .

2. Otoo-oyortey N. A battered women needs more than biological help. IPPF Med Bull 1997; 31(3): 5-6.

3. Bhuiya A, Sharmin T, Hanifi SM. Nature of domestic violence against women in a rural area of Bangladesh: implication for preventive interventions. $J$ Health Popul Nutr 2003; 21(1):48-54.

4. McGibbon A, Cooper L, Kelly L. What supportfi Hammersmith and Fulham council community police committee domestic violence. London: Polytechnic of North London, 1989.
5. Stanko E, Crisp D, Hale C, Lucraft H. Counting the costs: estimating the impact of domestic violence in the London Borough of Hackney. London: The children's Society and Hackney Safe Cities, 1997.

6. Robinson GE. Violence against women in North America. Arch Women Ment Health 2003; 6: 185-91.

7. Rotimi A, Violance in family: A preliminary investigation and overview of wife battery in Africa. Journal of International Women's Studies 2007; 9(1): 235-17.

8. Gayford JJ. Wife battery: a preliminary survey of 100 cases. BrMedJ 1975; 1: 194-7.

9. Helweg-Larsen K, Kruse M. Violence against women and consequent health problems: a register-based study. Scand JPublic Health 2003; 31: 51-7.

10. Grisso JA, Schwarz DF, Hirschinger N et al. Violent injuries among women in an urban area. $N$ Engl J Med 1999; 341: 1899-905.

11. Coker AL, Smith PH, Bethea L, King MR, McKeown RE. Physical health consequences of physical and psychological intimate partner violence. Arch Fam Med 2000; 9: 451-7.

12. Cascardi M, O'Leary KD, Schlee KA. Co-occurrence and correlates of posttraumatic stress disorder and major depression in physically abused women. J Fam Violence 1999; 14: 227-50.

13. Ratner PA. The incidence of wife abuse and mental health status in abused wives in Edmonton, Alberta. Can J Public Health 1993; 84: 246-9.

14. Steinmetz S: The Cycle of Violence: Assertive, Aggressive and Abusive Family Interaction. New York: Prayer, 1977.

15. Dunea G. The joy of wife-beating. Br MedJ 1977; 2: 565-6. 